\title{
Model Test Research on Bearing Mechanism of Underreamed Ground Anchor in Sand
}

\author{
Gang Guo $\mathbb{D}^{1,2}{ }^{1,2}$ Zhong Liu, ${ }^{2}$ Aiping Tang, ${ }^{1}$ Yibing Deng, ${ }^{3}$ and Jiqiang Zhang ${ }^{1}$ \\ ${ }^{1}$ School of Civil Engineering, Harbin Institute of Technology, Harbin 150090, China \\ ${ }^{2}$ Central Research Institute of Building and Construction of MCC Group, Beijing 100088, China \\ ${ }^{3}$ Ocean Environment and Engineering College, Shanghai Maritime University, Shanghai 201306, China \\ Correspondence should be addressed to Gang Guo; charlie4322@163.com
}

Received 3 April 2018; Revised 8 June 2018; Accepted 28 June 2018; Published 17 July 2018

Academic Editor: Roman Wan-Wendner

Copyright (C) 2018 Gang Guo et al. This is an open access article distributed under the Creative Commons Attribution License, which permits unrestricted use, distribution, and reproduction in any medium, provided the original work is properly cited.

To improve the capacity of ground anchors, scholars and engineers worldwide have developed various types of underreamed anchors with expanded anchor parts. Underreamed anchors have a completely different mechanism from traditional shaft anchors. The expanded section of an underreamed anchor induces an end bearing force to endure the uplift force similar to a reversed pile. Therefore, the total resistance of an underreamed anchor includes friction and end bearing force. To clarify the bearing mechanism of underreamed anchors, a series of model tests were performed using fiber Bragg grating (FBG) sensors and the photogrammetry measuring method. Based on the tests, the distribution and development of the friction and end bearing force of the underreamed anchor model were acquired by the FBG sensors when being pulled out. Moreover, the deformation state of the soil around the anchor model was observed by the digital photogrammetry measuring method. Finally, the interaction mechanism between an underreamed anchor and surrounding sand was obtained, which was identified as the inherent reason for the distribution and development law of the resistance of the underreamed anchor in sand.

\section{Introduction}

Geotechnical anchor technology transfers tensile forces from the constructions to the soil or rocks to endure the structural tensions resulting from the soil pressure, water pressure, or buoyancy. The complete objective of anchor technology is to maintain the stability of geotechnical structures. Since a geotechnical anchor was first applied in mine workings in 1912, it has been developed in the recent 100 years, and scholars reached the following consensus on the ultimate capacity of normal anchors [1-4]:

$$
\mathrm{F}=2 \pi \cdot R \cdot L \cdot \mu
$$

The above formula indicates that there are three factors that correlate with the anchor force: anchor length $L$, anchor radius $R$, and interaction strength between the anchor and soil $\mu$. Based on the above theory, scholars and engineers from various countries developed dozens of methods to improve the anchor force. Regarding the method of lengthening the anchor section, Barley [1] believed that the anchor force would not increase effectively with the lengthening of the anchor section once the length reached a certain value. In the recent decades, engineers have generally realized that increasing the diameter of a part of the anchor section is an effective approach for improving the anchor force. Liao $[5,6]$ in Taiwan described a cone-shaped anchor technology, Massarsch [7] developed the Soilexanchor system, Hobst and Zajic [8] reported the blasting anchor method, Cheng [9] produced a type of deep mixing anchor, Park [10] simulated underreamed anchors by pulse discharge technology, Zhu [11] tested a kind of umbrella-shaped anchor, and Liu [12] reported an anticorrosive underreamed anchor with a capsule (see Figure 1).

Regarding the theory of underreamed anchors, increasing the diameter of a part of the anchor section can not only improve the friction area between the anchor and corresponding soil but also convert the shaft anchor mechanism into an end bearing mechanism with friction. The diagram of the mechanism of an underreamed anchor is shown in Figure 2. 

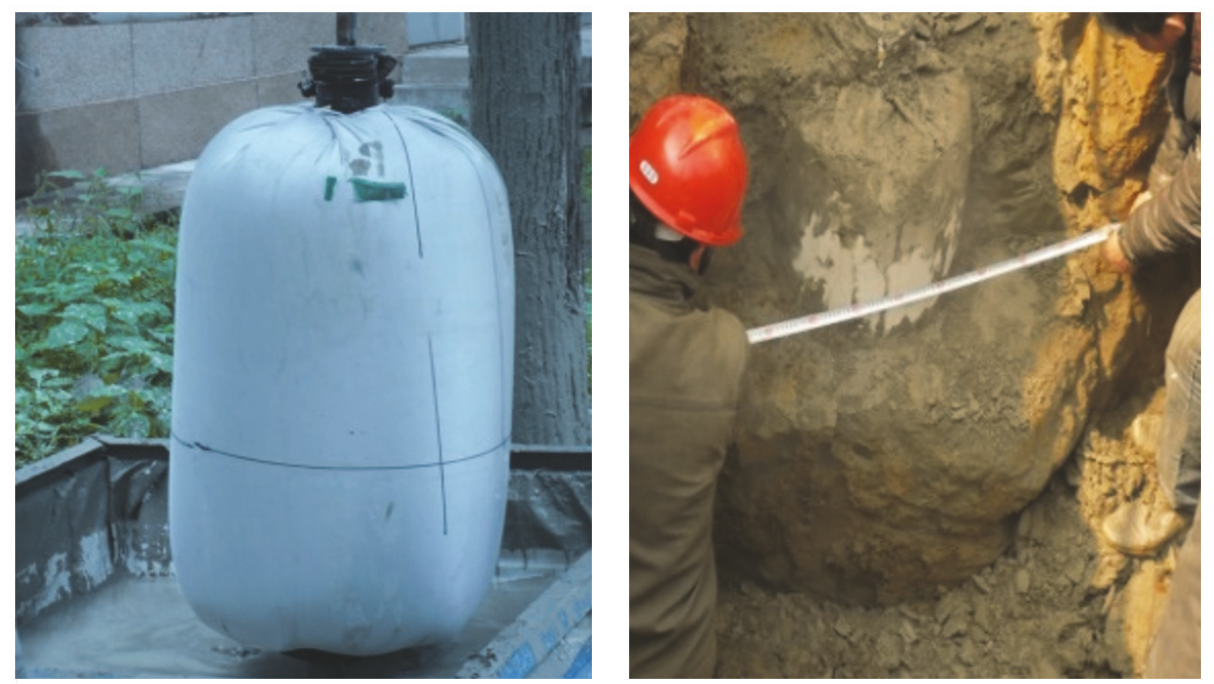

Figure 1: Photos of underreamed ground anchor with capsule.

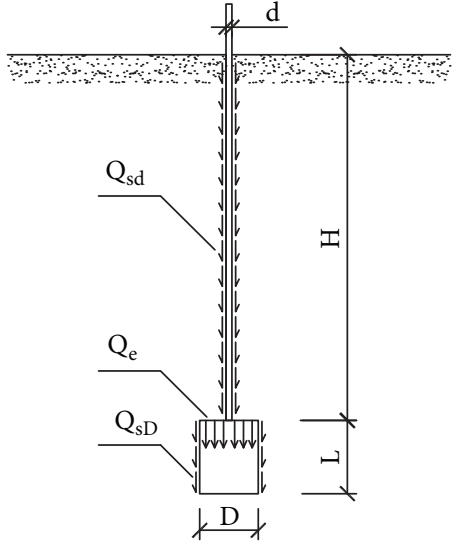

FIGURE 2: Diagram of the force distribution of an underreamed anchor.

With respect to theory, the British code of practice for grouted anchors (BS8081:2015) [13] and Chinese technical specification for underreamed anchors by jet grouting (JGJ/T282-2012) [14] led to different calculation methods. Moreover, Little John [15] and Bassett [16] separately reported empirical calculation methods. Zeng [17] derived a calculation method based on the earth pressure theory. Zhang [18] presented a predicting method of underreamed anchors based on a nonlinear load transfer method. Being limited by test methods, the above research results were obtained from simple theoretical derivations or statistical induction without considering the basis of the real interaction mechanism between the anchors and surrounding soil. Therefore, not only the formula types but also the calculation results of the above theories are quite different. In recent years, Hsu $[19,20]$ used a numerical simulation method to analyze the bearing mechanism of underreamed anchors. However, all the above research studies are not sufficient for the complex geotechnical problems. Both determining the real bearing mechanism of underreamed anchors and deriving the real interaction relationship between an anchor and surrounding soil lay a foundation for proposing a practical formula for the ultimate capacity of an underreamed anchor.

With the development of the geotechnical test technique, it has become possible to measure the deformation inside the soil and minor displacements of multiple points. Moreover, modern techniques provide the technical basis to identify the anchor force and observe the reaction mechanism of the corresponding soil.

In this study, the sensing technique of fiber Bragg grating (FBG) for strain measurement and a photogrammetry measuring technique were adopted. In the first test, a unique model of an underreamed anchor with FBG sensors was designed. Using the model, each part of the anchor force was distinguished and the development law was studied. In the second part, the digital photogrammetry measuring method was adopted and deformation of the soil around the underreamed anchor was observed. The test result explained the reason for examining the performance of the bearing mechanism of the underreamed anchor in the first test. The test results will assist in understanding the bearing mechanism and designing the formula for achieving the ultimate capacity of underreamed anchors practically.

\section{Mechanism Analysis of the Resistance of an Underreamed Anchor}

2.1. Introduction of Grating Measurement Technology. To measure multiple targets with a small deformation in a small space, the FBG sensing technology was adopted in the test. FBG technology is a measurement sensing technology to obtain the variations in surrounding physical quantities such as the strain and temperature. When one or more of the physical quantities change, the grating pitch is either elongated or shortened and the reflected wavelength shifts by $\Delta \lambda_{B}$ (see Figure 3). By determining the value of wavelength 


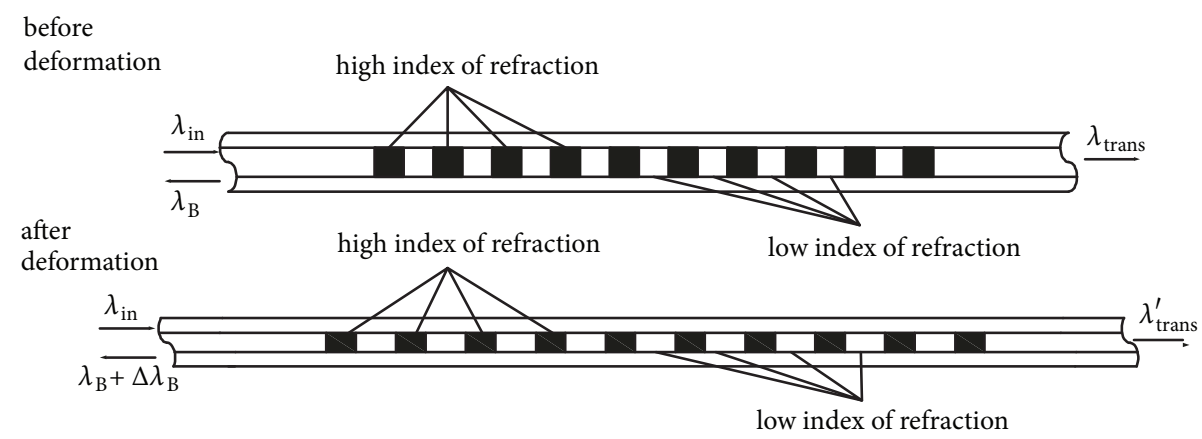

FIGURE 3: Schematic diagram of an FBG sensor.

shift $\Delta \lambda_{B}$ and establishing the relationship between the wavelength shift and target quantity, the variations in the target physical quantities such as strain and temperature can be acquired.

2.2. Test Program and Execution. To obtain quantitative results, the underreamed anchor models were designed with a geometric similarity ratio of 1:10. To achieve the aim of distinguishing the friction and end bearing force of an underreamed anchor, the designed model consisted of a hollow expanded section with a length of $250 \mathrm{~mm}$ and diameter of $100 \mathrm{~mm}$. On one end of the expanded section, a pressure sensing terminal with three sensing rings and twelve FBG sensors was set. There was a small gap between the pressure sensing terminal and hollow expanded section. A hollow rod with three FBG sensors connected the hollow expanded section and base of the pressure sensing terminal. On the base of the sensing terminal, a rebar with a length of 1200 $\mathrm{mm}$ and diameter of $10 \mathrm{~mm}$ was vertically fixed to simulate the normal anchor section and free section separately. Inside the above-mentioned three sensing rings of the pressure sensing terminal, three measuring columns at $90^{\circ}$ to each other were set. Between every two neighbour sensing rings, there sets a rubber isolating ring; there is also an isolating ring between the inner sensing ring and the rebar. From the deformations of the FBG sensors in the measuring columns, the distribution of the end bearing force and the total end bearing force could be obtained. The hollow rod between the sensing terminal and hollow expanded section was for measuring the friction of the expanded section because it deformed with the moving of the hollow expanded section. When an upward force is applied on the top of the rebar, the base moves synchronously with the rebar. The twelve FBG sensors on the measuring columns deform with the moving of the sensing rings under sand pressure. And the top of the hollow rod moves with the base of the pressure sensing terminal; the bottom of the hollow rod moves with the hollow expanded section under side friction. From the measured load, the end bearing force, and the friction of the expanded section, the friction of the normal section could be obtained. The complete underreamed anchor model with FBG sensors included in the expanded section with a diameter of $100 \mathrm{~mm}$ and length of $250 \mathrm{~mm}$ and a normal section with a diameter of $10 \mathrm{~mm}$ is shown in Figure 4.
To ensure the soil is uniform and repeatable, in each test, the foundations were formed with the stratified sand raining method [21, 22]. During the foundation forming procedure, the sand poured from the sand box, which was 1.0 $\mathrm{m}$ above the foundation box. When the sand level was equal to or higher than the foundation box frame, the sand raining operation was paused; the foundation was levelled off slowly by scraper. Then the next foundation box layer was set onto the foundation box, and the sand raining operation was continued. Through verification test, it was found that when the height of sand raining was more than $0.8 \mathrm{~m}$, the sand density was uniform. The sand used in the tests was medium silica sand, and the physicomechanical parameters of the foundation are listed in Table 1.

Tests were designed with various embedment depths of the model anchor to analyze the distribution and development of the resistance, as presented in Table 2. In this study, the embedment depth, $\mathrm{H}$, is the distance between the upper surface of the expanded section and surface of the foundation, as shown in Figure 2. Moreover, shaft anchors made of screw bars with diameters $8 \mathrm{~mm}, 10 \mathrm{~mm}$, and $12 \mathrm{~mm}$ were also designed for comparison.

The test system is depicted in Figure 5. In the test, an electrical resistance strain sensor is used as tension sensor, whose measuring range is $10000 \mathrm{~N}$, and the accuracy is $0.01 \mathrm{~N}$. Two grating scales are adopted for measuring displacement, whose measuring range is $100 \mathrm{~mm}$, and the accuracy is 0.05 $\mathrm{mm}$. A dual channel FBG interrogator is used for recording the wavelength values, whose accuracy is $0.001 \mathrm{~nm}$, and the measuring range of an FBG sensor is $5000 \mu \varepsilon$. A single load step is maintained for $3 \mathrm{~min}$, and then the operator records the total load value (Q) from the tension sensor, displacement (s) from the displacement sensor, and wavelength values from the FBG interrogator. When the displacement reaches 60 $\mathrm{mm}$, the test is stopped. Following this the operator calculates the friction of the expanded section $\left(\mathrm{Q}_{\mathrm{sD}}\right)$ and end bearing force $\left(Q_{e}\right)$ of each sensing ring from the FBG wavelengths. Subsequently, the friction of the normal section $\left(Q_{s d}\right)$ is derived from the following formula:

$$
Q_{s d}=Q-Q_{e}-Q_{s D}
$$

2.3. Load versus Displacement Curves of Underreamed Anchors. The load (Q) versus displacement (s) curves of the 

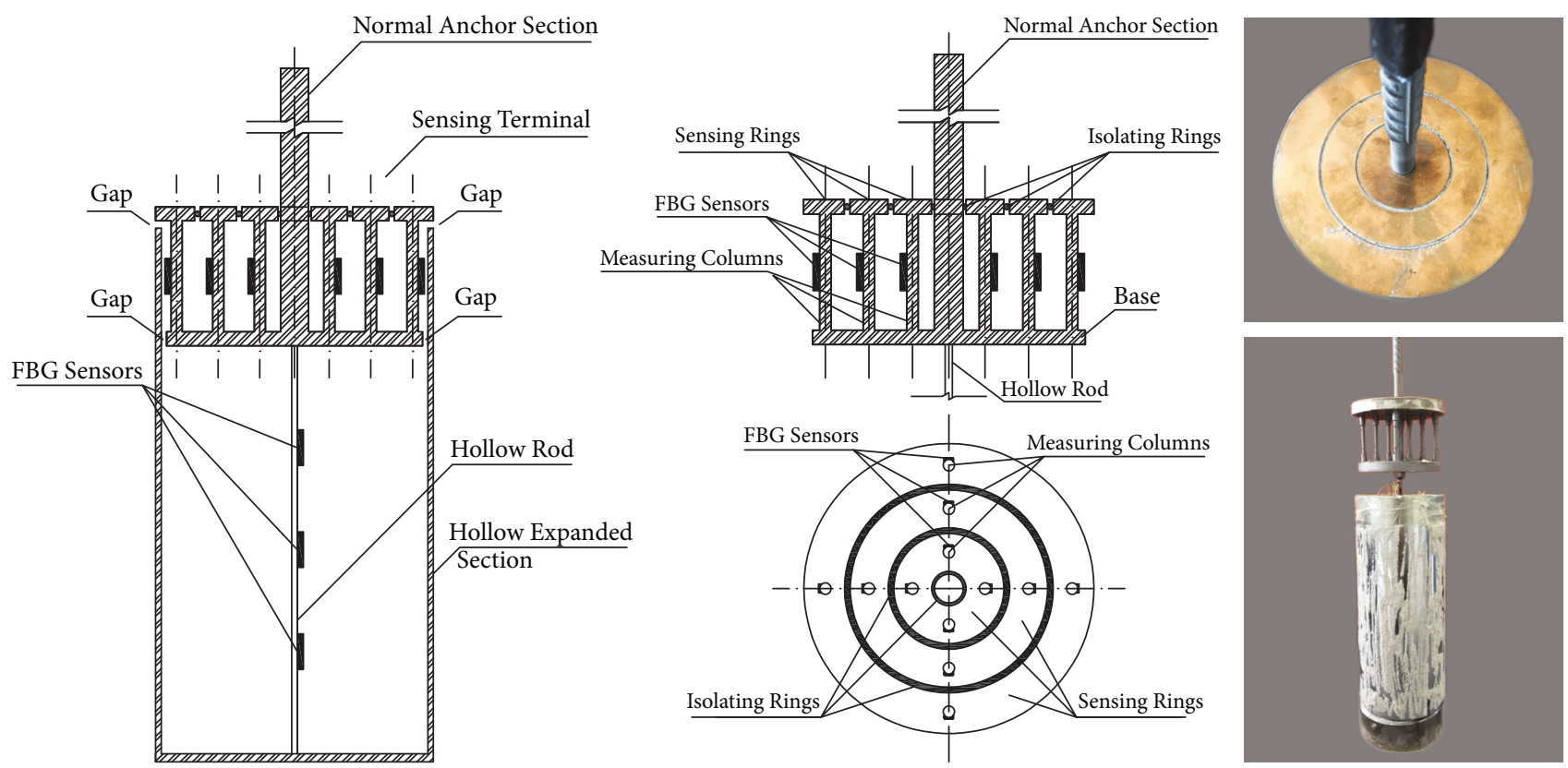

FIGURE 4: Design drawings and photos of the underreamed anchor model with FBG sensors.

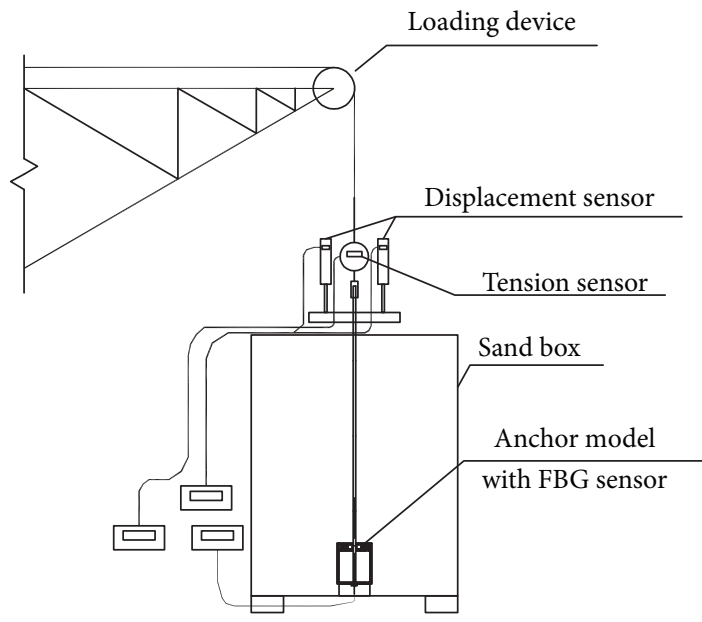

(a)

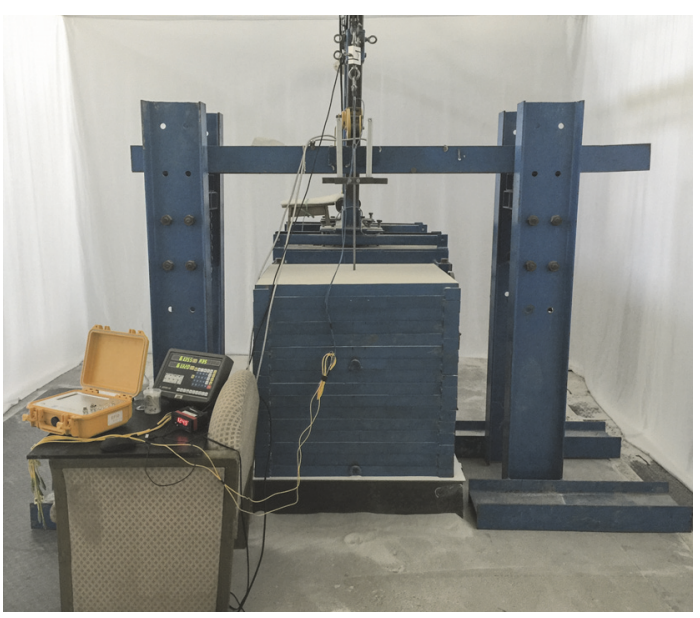

(b)

FIgURE 5: Model test system of the mechanism analysis of the underreamed anchor. (a) Design drawing of test system. (b) Model test site.

TABLE 1: Physical and mechanical parameters of the model foundations.

\begin{tabular}{|c|c|c|c|c|c|}
\hline $\begin{array}{l}\text { Density } \\
/ \mathrm{g} \cdot \mathrm{cm}^{-3}\end{array}$ & $\begin{array}{c}\text { Coefficient of } \\
\text { uniformity }\end{array}$ & $\begin{array}{c}\text { Friction angle } \\
/^{\circ}\end{array}$ & $\begin{array}{l}\text { Cohesion } \\
/ \mathrm{kN} \cdot \mathrm{m}^{-2}\end{array}$ & $\begin{array}{c}\text { Poisson's } \\
\text { ratio/v }\end{array}$ & Uniformity coefficient \\
\hline 1.49 & 1.9 & 40.0 & 0.0 & 0.26 & 1.9 \\
\hline $\begin{array}{l}\text { Relative } \\
\text { density }\end{array}$ & Void ratio & $\mathrm{D}_{50} / \mathrm{mm}$ & $\begin{array}{l}\text { Specific } \\
\text { gravity }\end{array}$ & $\begin{array}{c}\text { Water } \\
\text { content } / \%\end{array}$ & Curvature coefficient \\
\hline 0.673 & 0.79 & 0.35 & 2.67 & 0.0 & 1.18 \\
\hline
\end{tabular}

TABLE 2: Test program on the mechanism analysis of the under-reamed anchor.

\begin{tabular}{lcccccc}
\hline Test No. & 1 & 2 & 3 & 4 & 5 & 5 \\
\hline Embedment depth/mm & 850 & 750 & 650 & 550 & 450 & 350 \\
\hline
\end{tabular}




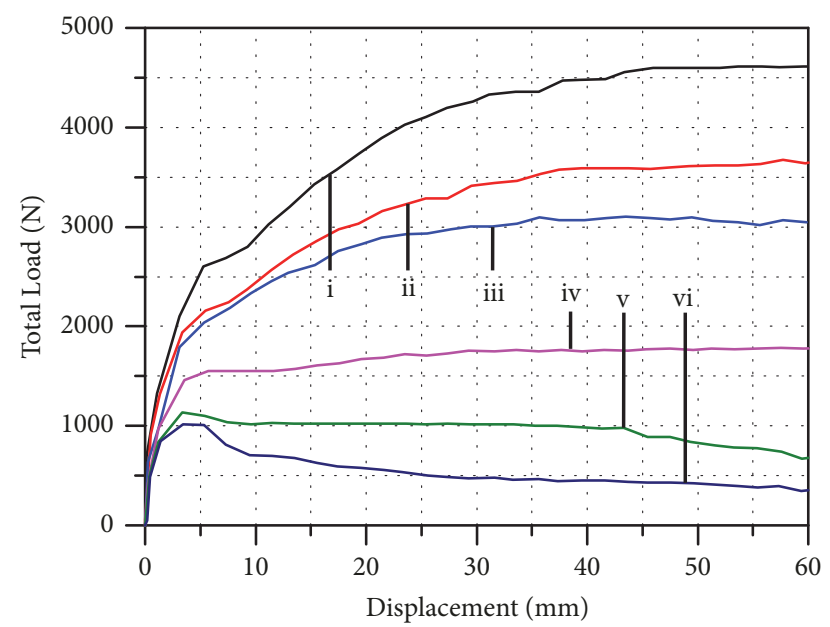

FIgURE 6: Q-s curves of underreamed anchors with (i) $\mathrm{H}=850 \mathrm{~mm}$; (ii) $\mathrm{H}=750 \mathrm{~mm}$; (iii) $\mathrm{H}=650 \mathrm{~mm}$; (iv) $\mathrm{H}=550 \mathrm{~mm}$; (v) $\mathrm{H}=450 \mathrm{~mm}$; (vi) $\mathrm{H}=350 \mathrm{~mm}$.

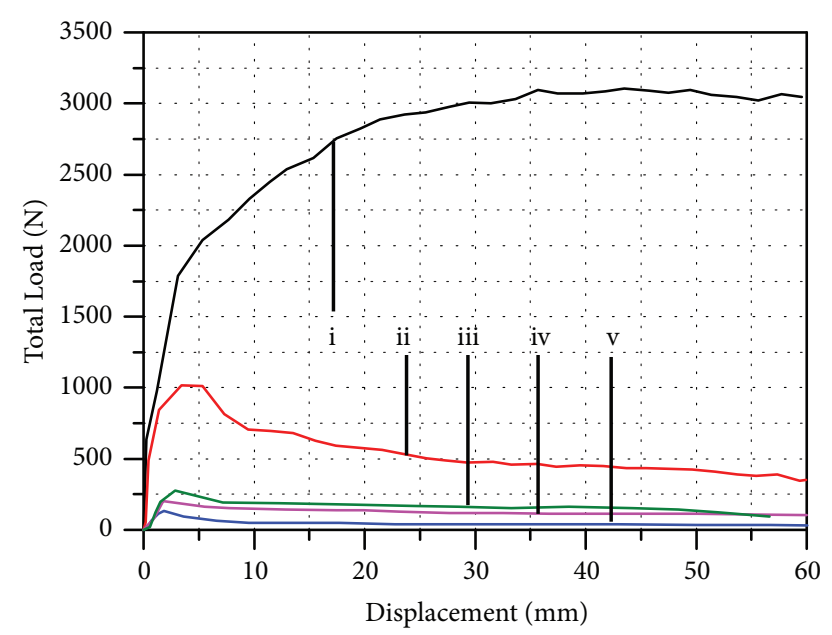

FIgURE 7: Comparative Q-s curves of underreamed anchors and shaft anchors with (i) $\mathrm{H}=650 \mathrm{~mm}$; (ii) $\mathrm{H}=350 \mathrm{~mm}$; (iii) $\mathrm{d}=12 \mathrm{~mm}$ of shaft anchor; (iv) $d=10 \mathrm{~mm}$ of shaft anchor; (v) $d=8 \mathrm{~mm}$ of shaft anchor.

underreamed anchors at various embedment depths are shown in Figure 6.

The six curves in Figure 6 show that the same underreamed anchor at different embedment depths has different behaviors. The Q-s curves of the anchors at deep embedment depths are monotonous curves, e.g., the anchors at the embedment depths of $550 \mathrm{~mm}-850 \mathrm{~mm}$. In contrast, the Q-s curves of the anchors at low embedment depths are nonmonotonous with peaks.

For analyzing the differences between the two classic curves, the curves for $\mathrm{H}=650 \mathrm{~mm}$ and $\mathrm{H}=350 \mathrm{~mm}$ are selected and exhibited in Figure 7. For comparison, the Q-s curves of the shaft anchors are also plotted in Figure 7.

The Q-s curve of the underreamed anchor in deep sand (short for deep anchor) in Figure 7 exhibits the behavior of a hardening development model. The bearing capacity of the deep anchor rapidly increases at the start of the loading. After a turning point, the displacement rate increases and the curve starts to flatten. Based on the trends in Figure 6, a deeper anchor has a larger curve slope and lower displacement rate. This is because deeper anchors are more constricted by the earth pressure and can bear more loads. Overall, the Q-s curve of a deep anchor undergoes a rising stage, turning stage, and large displacement stage.

The Q-s curve of the underreamed anchor embedded in shallow sand (referred to as shallow anchor) in Figure 7 exhibits the behavior of a softening development model. The bearing capacity of the shallow anchor also rapidly increases at the beginning of the loading, and the loading displacement develops to approximately $5 \mathrm{~mm}$, with the resistance reaching a peak point. Subsequently, the bearing capacity decreases sharply and finally starts to flatten; thus, the anchor only has a residual bearing capacity. Generally, the Q-s curve of a shallow anchor has three stages: rising stage, falling stage, and residual stage. There is a critical embedment depth to recognize an underreamed anchor a deep anchor or a shallow anchor.

The Q-s curves of the shaft anchors in Figure 7 are similar to the curve of a shallow anchor. Generally, shear failure occurs near the contact surface of the anchor and sand. The bearing mechanism of a shaft anchor is of a softening model.

2.4. Distribution of the Resistance of an Underreamed Anchor. The distribution and development of the resistance of the underreamed anchors at various embedment depths were acquired by the FBG sensors. Figure 8 summarizes the relationships of the total load $(\mathrm{Q})$, friction of the expanded section $\left(Q_{s D}\right)$, friction of the normal section $\left(Q_{s d}\right)$, and end bearing force $\left(\mathrm{Q}_{\mathrm{e}}\right)$ with the increase in the loading displacement of the underreamed anchor at an embedment depth of $850 \mathrm{~mm}$.

In the four curves in Figure 8(a), there are numerous differences between the $\mathrm{Q}_{e}-\mathrm{s}, \mathrm{Q}_{\mathrm{sD}}-\mathrm{s}$, and $\mathrm{Q}_{\mathrm{sd}}-\mathrm{s}$ curves. Among the curves, the $\mathrm{Q}_{\mathrm{e}}-\mathrm{s}$ curve is quite similar to the $\mathrm{Q}-\mathrm{s}$ curve; they are both monotonous increasing curves.

It is worth highlighting that the $\mathrm{Q}_{\mathrm{sD}}-\mathrm{s}$ curve has clear differences with the $\mathrm{Q}_{s d}-\mathrm{s}$ curve. The $\mathrm{Q}_{\mathrm{sD}}-\mathrm{s}$ curve exhibits a similar trend to the $\mathrm{Q}-\mathrm{s}$ curve of a shaft anchor. The reason is that the mechanical condition of the expanded section is similar to that of a shaft anchor. Moreover, the $\mathrm{Q}_{\mathrm{sd}}-\mathrm{S}$ curve has a different trend from the above two curves; it is a monotonous increasing curve. This is because the mechanical condition of the normal section of an underreamed anchor does not have a simple frictional mechanism state. In addition to the friction, the total load is acting on the top of the normal section and the force from the expanded section (sum of $Q_{e}$ and $\mathrm{Q}_{\mathrm{sD}}$ ) is acting on the bottom. Because of the constraint of the expanded section, a general failure of the normal anchor section of an underreamed anchor can hardly occur.

Figure 8(a) also shows the development relationships between the friction and end bearing force during loading. When the load displacement is less than $5 \mathrm{~mm}$, the friction plays a more important role in determining the total resistance. With the pulling displacement increases, the friction decreases after its peak value, whereas the end bearing force 


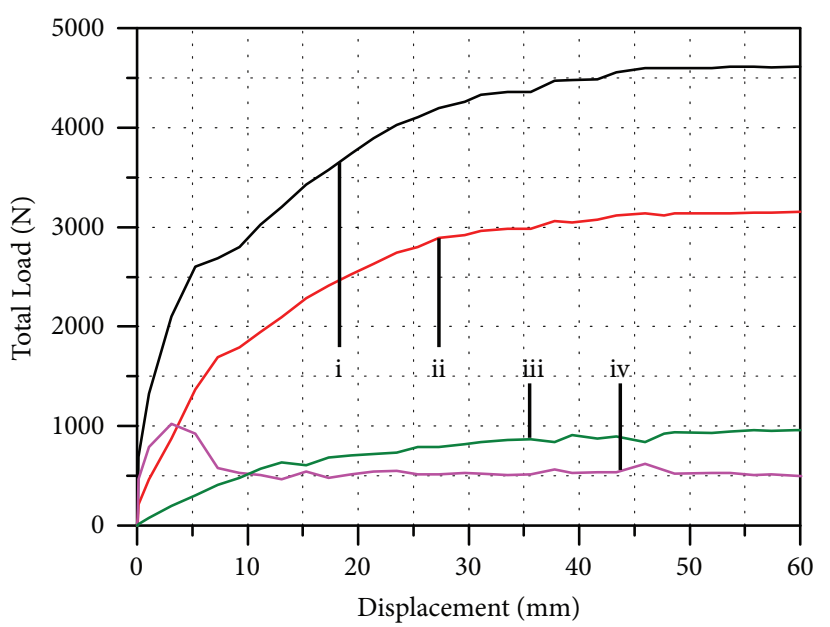

(a)

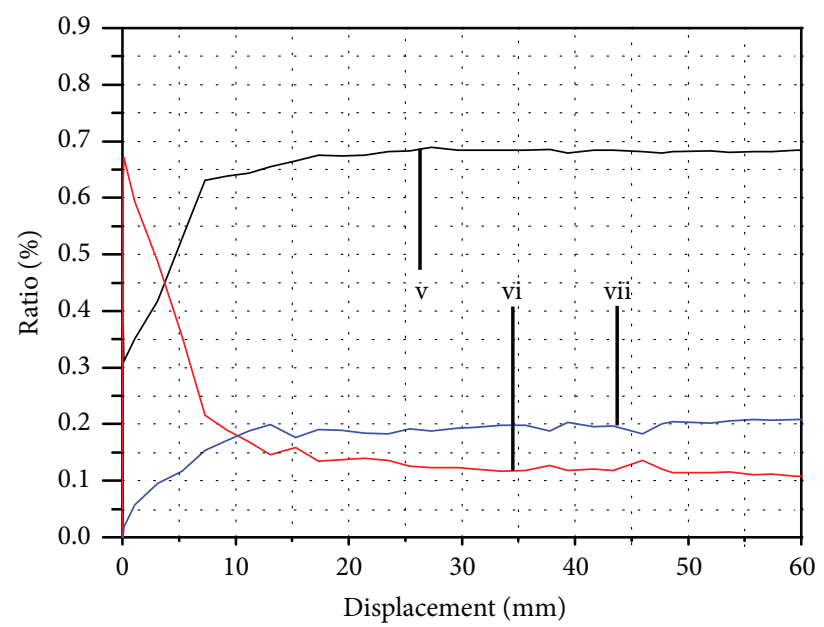

(b)

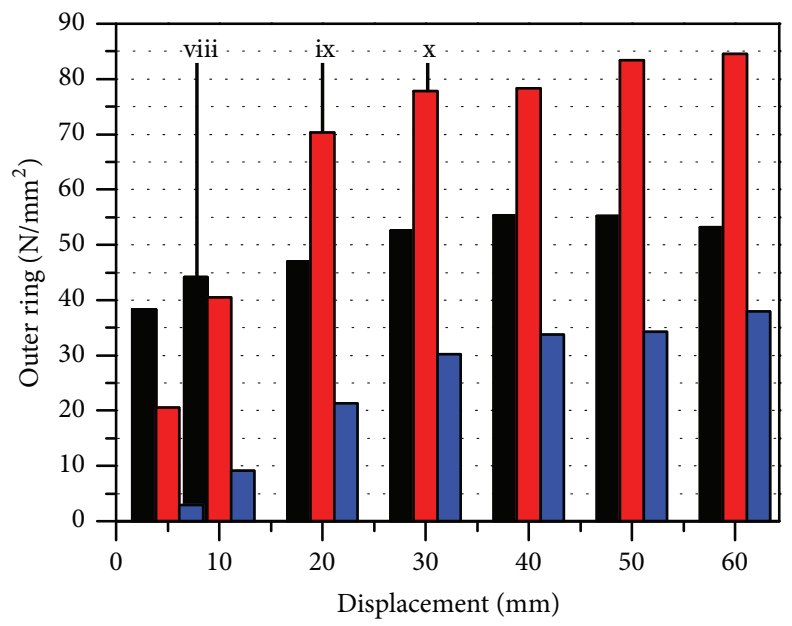

(c)

FIGURE 8: Graphics on the force distribution of the underreamed anchor embedded in $850 \mathrm{~mm}$. (a) Resistance of every anchor part, with (i) total load, (ii) end bearing force, (iii) friction of the expanded section, and (iv) friction of the normal section. (b) The percentages of (v) $\mathrm{Q}_{\mathrm{e}} / \mathrm{Q}$, (vi) $\mathrm{Q}_{\mathrm{sD}} / \mathrm{Q}$, and (vii) $\mathrm{Q}_{\mathrm{sd}} / \mathrm{Q}$. (c) The force distributions of (viii) the outer ring, (ix) the medium ring, and (x) the inner ring.

increases rapidly and accounts for $68 \%$ of the total resistance. The above phenomenon illustrates that when the load starts, first the friction takes effect and the total resistance is mainly from the friction. When the anchor is loaded to cause a sufficient displacement ( $8 \mathrm{~mm}$ in this test condition), the end bearing force takes effect and it is more dominant. To introduce the proportional relationships between each part of the resistance, Figure 8(b) depicts the percentages of $Q_{e} / Q$, $\mathrm{Q}_{\mathrm{sD}} / \mathrm{Q}$, and $\mathrm{Q}_{\mathrm{sd}} / \mathrm{Q}$. The trends reveal that the force of each part tends to be constant when the load displacement reaches $20 \mathrm{~mm}$. The end bearing force accounts for $68 \%$, friction of the expanded section accounts for $12 \%$, and friction of the normal section accounts for $20 \%$ of the total resistance.

In addition to the above resistance analysis, the test also focuses on the stress state on the upper surface of the expanded section. The mean stress on the upper faces of the three measurement rings can be obtained from the forces acquired by them. The force distributions of the three parts during some loading stage are illustrated in Figure 8(c). The histogram demonstrates that the outer part takes effect at the start of the loading, and, so, the stress is reduced on the inner parts, as shown in Figure 9(a).

With increasing load, the increasing amplitude of the stress on the outer part is reduced and tends to a constant. As the loading progresses, the stress on the medium part increases rapidly before a displacement of $30 \mathrm{~mm}$ is attained, after which it also tends to be constant. The stress on the inner part increases gradually, and it is always less than the stress on the outer or medium part. After the load displacement reaches $20 \mathrm{~mm}$, the stress state is similar to a wave, i.e., higher on the medium and lower on the outer and inner parts, as shown in Figure 9(b). The reason is that there is a stress concentration between the outer part and surrounding soil at the start of the loading. As the loading progresses, the anchor is sufficiently displaced that the surrounding soil tends to undergo shear failure, leading the outer part to unload. As the load increases, the medium part is enlarged and the peak stress moves toward it, as shown in Figure 9(b). Regarding the 


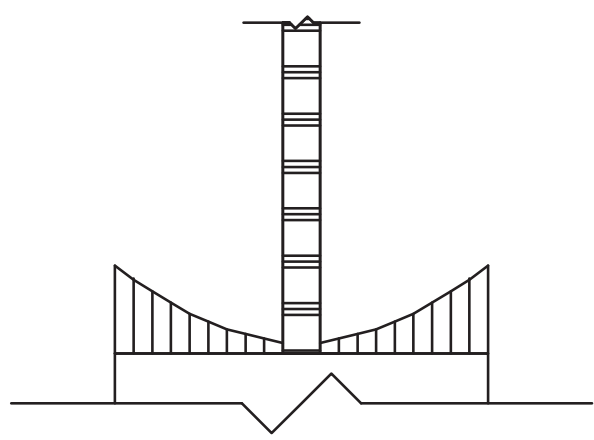

(a)

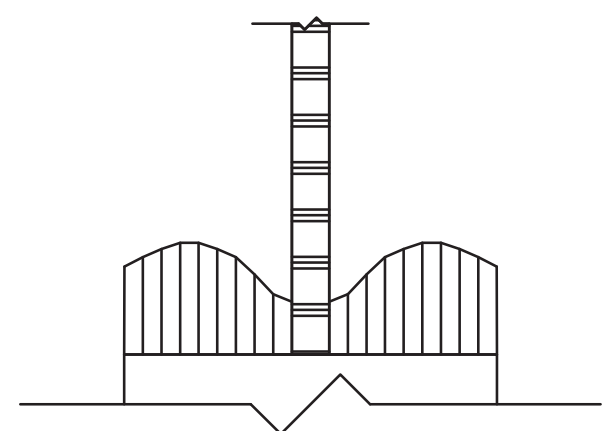

(b)

Figure 9: Diagram of stress state on the upper face of the expanded section.

stress on the inner part, when the load becomes still higher, the soil near the outer and medium parts undergoes failure and the peak stress is expected to move to the inner part. However, in the test condition, this was not observed. Overall, the stress performance on the upper surface of a deep anchor is the same as that of an inverted rigid foundation in sand.

Other test results are acquired by the same method. Consider $\mathrm{H}=550 \mathrm{~mm}$ as an example, as shown in Figure 10. The curves in Figures 10(a) and 10(b) illustrate that the resistance distribution on the anchor at $\mathrm{H}=550 \mathrm{~mm}$ is the same as that on the anchor at $\mathrm{H}=850 \mathrm{~mm}$. However, according to Figure $10(\mathrm{c})$, there are still differences in the stress state on the upper surface of the expanded section under the two conditions. In the chart, the outer stress increases before the load displacement becomes $10 \mathrm{~mm}$, and, after this, the stress decreases. This trend is quite different from that on the anchor at $\mathrm{H}=850 \mathrm{~mm}$. The reason is that the earth pressure of the shallower anchor is lower, and the confining pressure is not sufficient to sustain the soil around the anchor during loading. Therefore, with the increase in displacement, the sand around the expanded section tends to undergo shear failure easily.

To identify the differences between a deep and shallow anchor, the test data of the shallow anchor at $\mathrm{H}=350 \mathrm{~mm}$ is selected as shown in Figure 11.

The four curves in Figure 11(a) exhibit that first the friction takes effect on the shallow anchor. Moreover, the behavior of the end bearing force on the shallow anchor is different from that on the deep anchor. The former attains a peak after a small increase in progress and then it decreases. The peak of the end bearing force is shorter and the corresponding displacement is longer than that of the friction. According to the $\mathrm{Q}_{\mathrm{sD}}-\mathrm{s}$ curve, different from deep anchors, friction plays the most important role in the total resistance of the shallow anchor.

Figure 11(b) exhibits the proportion of the three partial anchor forces in the total resistance. Before a displacement of $6 \mathrm{~mm}$, the shear force accounts for approximately $60 \%$ of the total resistance and friction accounts for the remaining part. Beyond $6 \mathrm{~mm}$, the percentage of the end bearing force increases and it accounts for approximately $60 \%$ of the total resistance. It is noteworthy that, beyond the loading displacement of $6 \mathrm{~mm}$, the anchor undergoes failure according to the
Q-s curve. Therefore, it is irrelevant that the end bearing force takes effect after the displacement of $6 \mathrm{~mm}$. This illustrates that the shear force dominates the total resistance of a shallow anchor in another aspect.

Comparing Figures $8(\mathrm{c})$ and $11(\mathrm{c})$, the stress state on the upper surface of the shallow anchor has significant differences from that of deep anchors. For the shallow anchor, the outer stress takes effect at the start of the loading. As the loading displacement increases, the outer stress value decreases directly and the medium stress decreases after slightly increasing. The reason is that the earth pressure on the shallow anchor is extremely small to sustain the resistance of the anchor. The soil around the shallow anchor undergoes shear failure more easily. When the anchor is pulled out, first the soil near the outer part undergoes shear failure, followed by the soil near the medium part. This leads to a large-scale shear failure of the soil above the upper face of the shallow anchor, and, so, the total resistance decreases.

The above analysis reveals that the end bearing force is the main component in the resistance of an underreamed anchor. Accordingly, the $\mathrm{Q}_{\mathrm{e}}-\mathrm{s}$ curves of the underreamed anchor in the test program are summarized in Figure 12(a). Furthermore, the maximum end bearing force values $\left(\mathrm{Q}_{\mathrm{emax}}\right)$ during loading of all the anchors are collected, and the relation curve of $\mathrm{Q}_{\mathrm{emax}}-\mathrm{H}$ is shown in Figure 12(b).

By the trend of $\mathrm{Q}_{\mathrm{emax}}-\mathrm{H}$ in the tests, the quantitative relationship between the end bearing force of an underreamed anchor and its embedment depth can be stated as a quartic polynomial with the correlation coefficient of 0.988 :

$$
\begin{aligned}
\mathrm{Q}_{\text {emax }}= & 1.446+3.777 H-0.021 H^{2}+4.905 \times 10^{-5} H^{3} \\
& -2.862 \times 10^{-8} H^{4}
\end{aligned}
$$

It is worth highlighting that the $\mathrm{Q}_{\mathrm{e}}-\mathrm{s}$ curves of deep anchors are monotonous increasing, a straight line can be fitted for the curve of $\mathrm{Q}_{\mathrm{emax}}-\mathrm{H}$ of deep anchors $(\mathrm{H}=550 \mathrm{~mm}$ and above), the fitting equation is as follows, and the correlation coefficient is 0.9917 :

$$
\mathrm{Q}_{\text {emax }}=-2139.284+6.237 \mathrm{H}
$$

It should be noted that the above coefficients of the predictive equations are all valid under the experimental condition. 


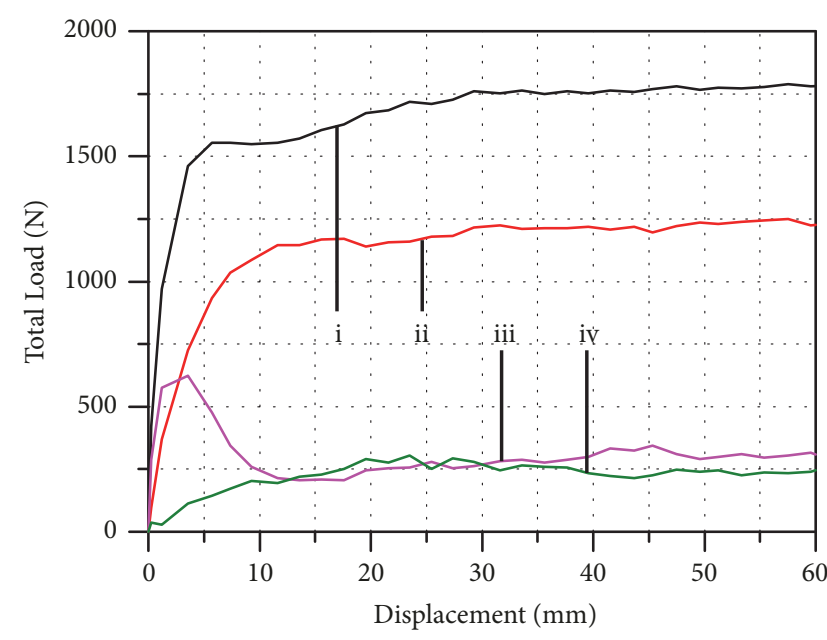

(a)

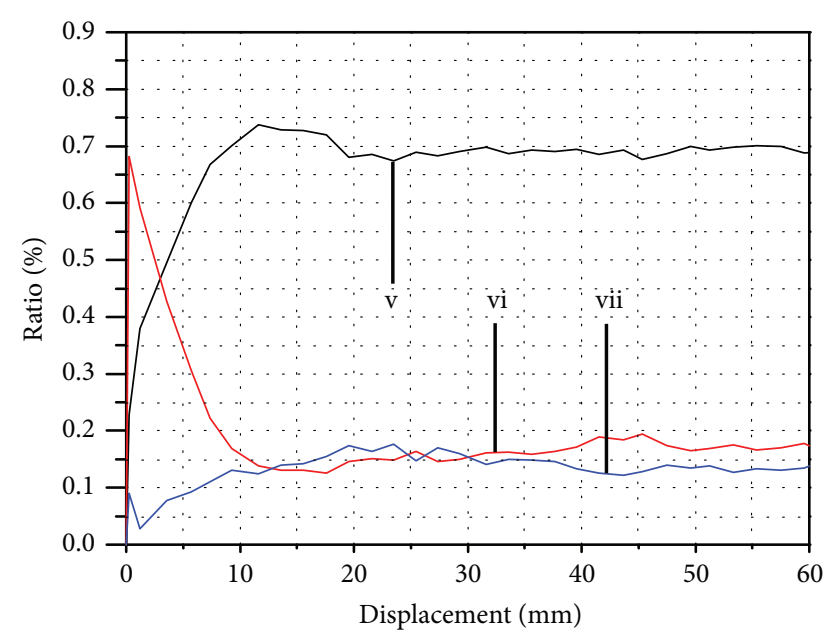

(b)

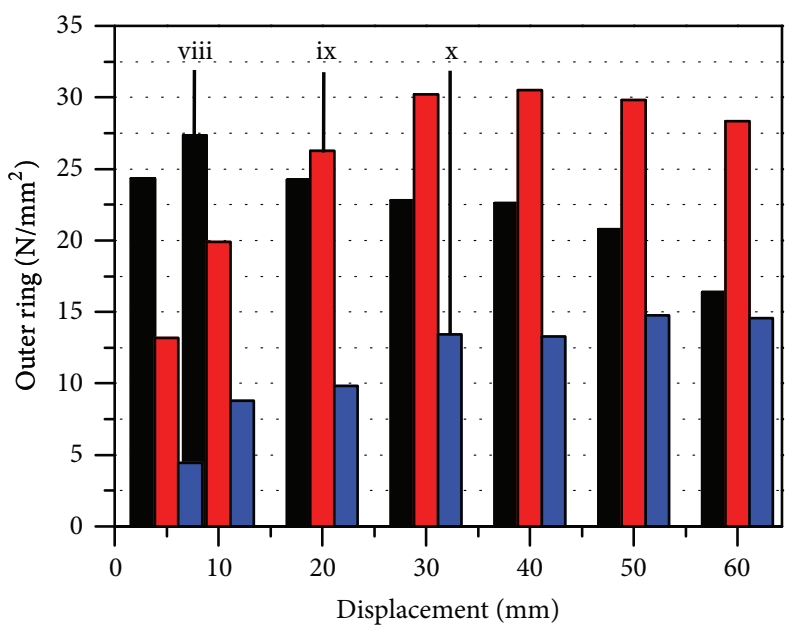

(c)

FIGURE 10: Graphics on the force distribution of the underreamed anchor embedded in $550 \mathrm{~mm}$. (a) Resistance of every anchor part, with (i) total load, (ii) end bearing force, (iii) friction of the expanded section, and (iv) friction of the normal section. (b) The percentages of (v) $\mathrm{Q}_{\mathrm{e}} / \mathrm{Q}$, (vi) $\mathrm{Q}_{\mathrm{sD}} / \mathrm{Q}$, and (vii) $\mathrm{Q}_{\mathrm{sd}} / \mathrm{Q}$. (c) The force distributions of (viii) the outer ring, (ix) the medium ring, and ( $\mathrm{x}$ ) the inner ring.

And more customized experiments need to be performed for anchors with different dimensions and soil properties to extent the calculating model.

Overall, it can be concluded that there is a strong positive correlation between the end bearing force of an underreamed anchor and its embedment depth. Moreover, the relationship between the end bearing force of a deep underreamed anchor and its embedment depth is a significant linear correlation.

\section{Analysis of the Deformation Mechanism of the Soil around the Anchor}

3.1. Introduction of the Digital Photogrammetry Technique. The performance and stability of a geotechnical component typically depend on the surrounding soil. In recent decades, with the development of imaging techniques, researchers have used film cameras, digital cameras, X-ray, laser tomography, interference imaging, and holography to identify the deformation states of soil. The above deformation measurement methods need either unique equipment or distinct materials. With the development and propagation of digital cameras; digital photogrammetry based on digital cameras has the advantages of a simple device, clear principle, and sufficient accuracy.

To analyze the deformation state of the soil around the underreamed anchor, the three-step algorithm of digital photogrammetry [23] based on the translation and rotation of soil points is adopted. The method simplifies the complex deformation process of soil points into translation and rotation. Using 3-4 fixed points (mark points) around the area to be measured, the image coordinates and real coordinates of the soil can be correlated. The units of measurement for image coordinates is pixel, and units of measurement for actual coordinates are usually millimeter and micrometer. By calculating the coordinate variations of the target points in a sequence of images, the displacements of target points can be obtained directly. The process of calculating the strain of a 


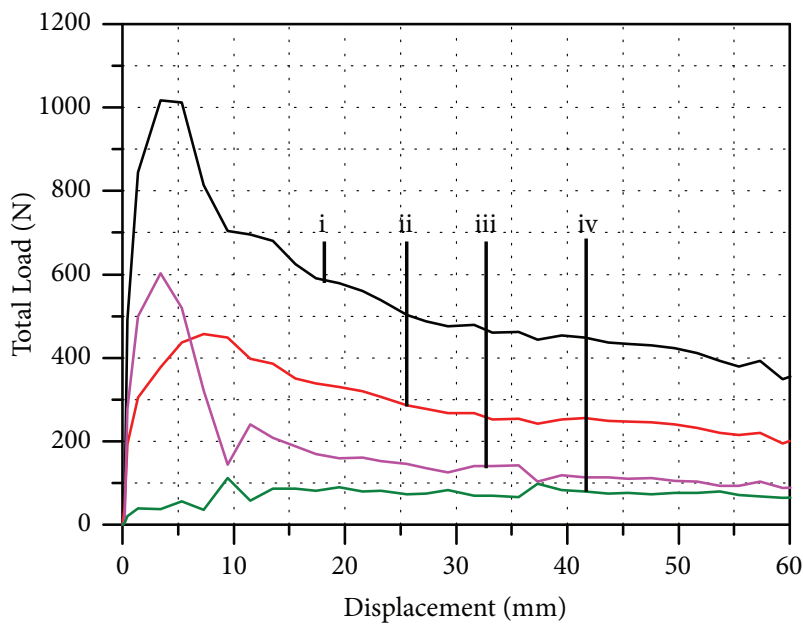

(a)

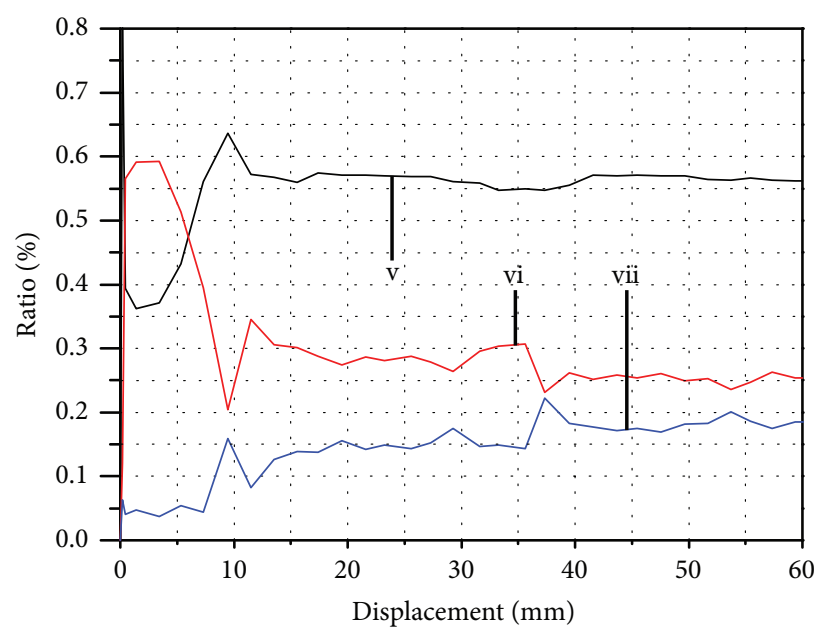

(b)

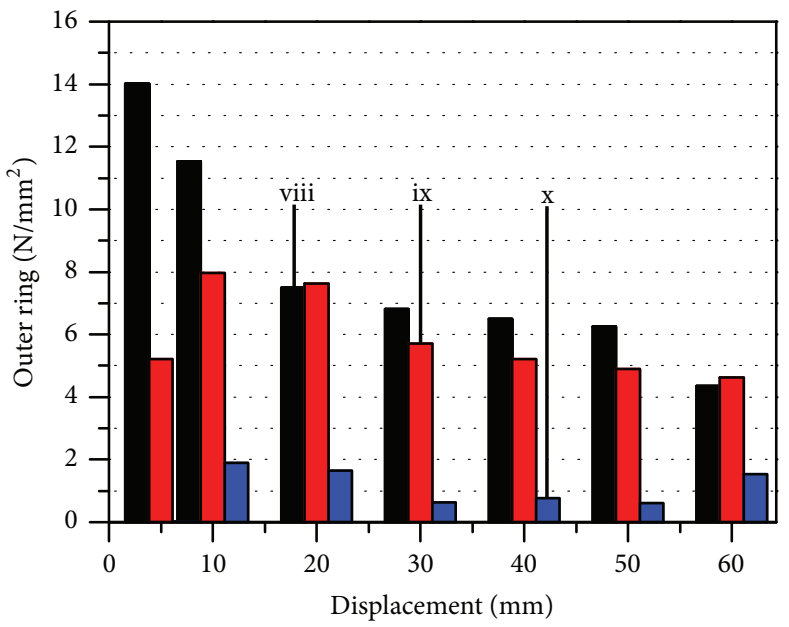

(c)

FIGURE 11: Graphics on the force distribution of the underreamed anchor embedded in $350 \mathrm{~mm}$. (a) Resistance of every anchor part, with (i) total load, (ii) end bearing force, (iii) friction of the expanded section, and (iv) friction of the normal section. (b) The percentages of (v) $\mathrm{Q}_{\mathrm{e}} / \mathrm{Q}$, (vi) $\mathrm{Q}_{\mathrm{sD}} / \mathrm{Q}$, and (vii) $\mathrm{Q}_{\mathrm{sd}} / \mathrm{Q}$. (c) The force distributions of (viii) the outer ring, (ix) the medium ring, and ( $\mathrm{x}$ ) the inner ring.

target zone is similar to the one in FEM. First of all, the target scope is divided into quadrangle mesh; the central point of a grid cell contains strain data. One grid cell with four target points can be treated as quadrangle element in FEM. When the coordinates and displacements of the target points are known, the displacement and strain value of a grid cell can be calculated by quadrangle isoparametric method. When obtaining the displacement of points and strain of grid cells in the images, the actual sand deformation state can be acquired.

3.2. Test Program and Devices. In the research work on geotechnical anchor techniques, in addition to the macroscopic law of resistances, the analysis of the mechanical response of the soil around the anchors is an effective approach to identifying the main causes of the performance of the anchor resistance. The symmetrical model test method was adopted to observe and analyze the soil deformation state around the underreamed anchor. In the test, a vertical symmetrical model was designed according to the mechanical symmetrical principle. Moreover, the deformation state was acquired by using the transmit glass in front of the model and described by the digital photogrammetry technique.

The sand specimen was the same as the above model test, and the parameters are listed in Table 1 . The sand box was height adjustable, and its dimensions were width 700 $\mathrm{mm}$, length $800 \mathrm{~mm}$, and height $1000 \mathrm{~mm}$. To ensure good boundary conditions, Vaseline was used between the front glass and anchor model. According to the theory of photogrammetry, four mark points were set in the four corners of the glass, as shown in Figure 13.

The anchor model was also a symmetrical model, with a diameter of $100 \mathrm{~mm}$. The test program used to analyze the reaction of the soil around the deep anchor and shallow anchor is presented in Table 3.

In the test, the loading process was a displacementcontrol mode. A D80 digital single-lens reflex camera and a prime lens with the focal length of $50 \mathrm{~mm}$ are adopted. At the start of the test, the operator took a photo of the target 
TABLE 3: Test program on soil deformation state around underreamed anchors.

\begin{tabular}{lccc}
\hline No. & $\begin{array}{c}\text { Length of expanded } \\
\text { section } \\
\text { L/mm }\end{array}$ & $\begin{array}{c}\text { Diameter of expanded } \\
\text { section } \\
\text { D/mm }\end{array}$ & $\begin{array}{c}\text { Embedment depth } \\
\mathrm{H} / \mathrm{mm}\end{array}$ \\
\hline 1 & 100 & 100 & 850 \\
2 & 100 & 100 & 350 \\
\hline
\end{tabular}

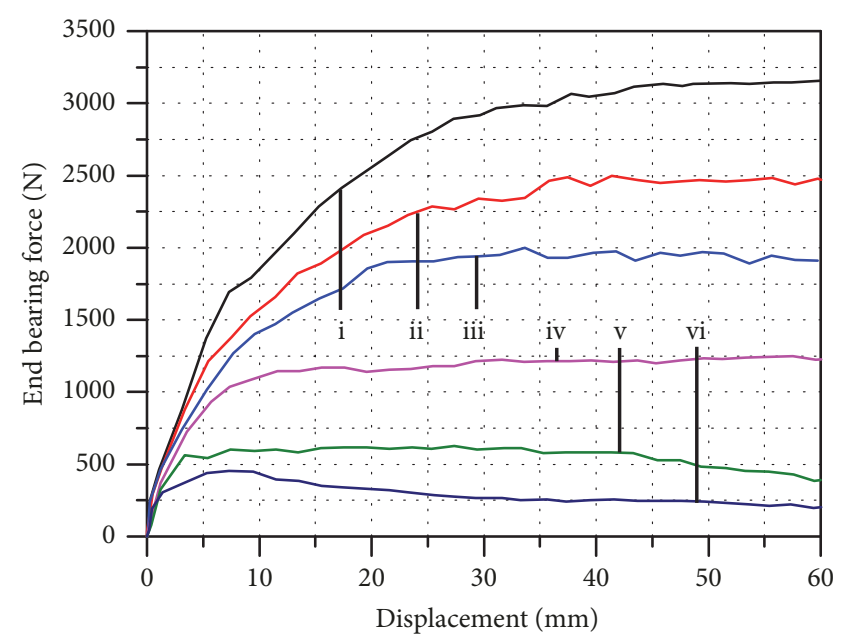

(a)

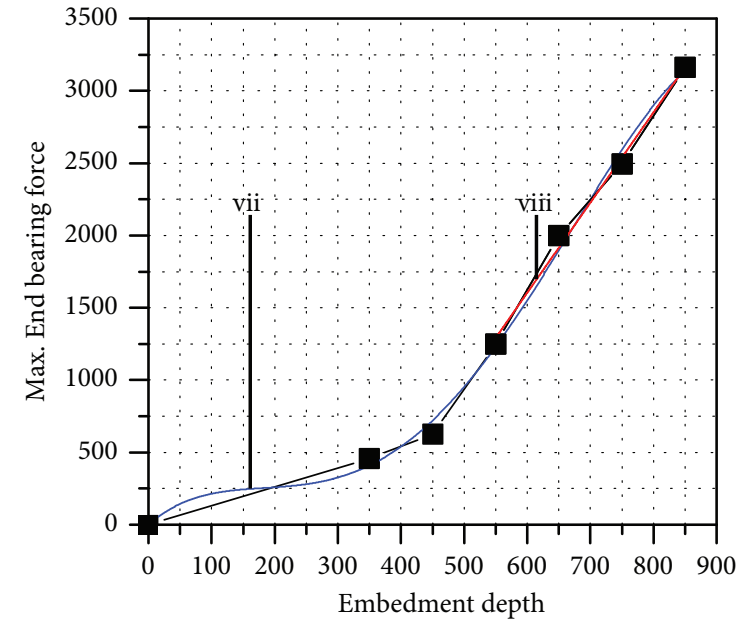

(b)

FIGURE 12: The development curves of end bearing forces with (a) load displacement growth at the embedment depth of (i) 850mm, (ii) $750 \mathrm{~mm}$, (iii) $650 \mathrm{~mm}$, (iv) $550 \mathrm{~mm}$, (v) $450 \mathrm{~mm}$, and (vi) $350 \mathrm{~mm}$; (b) the variation of embedment depth with (vii) quartic polynomial curve and (viii) linear increasing line.
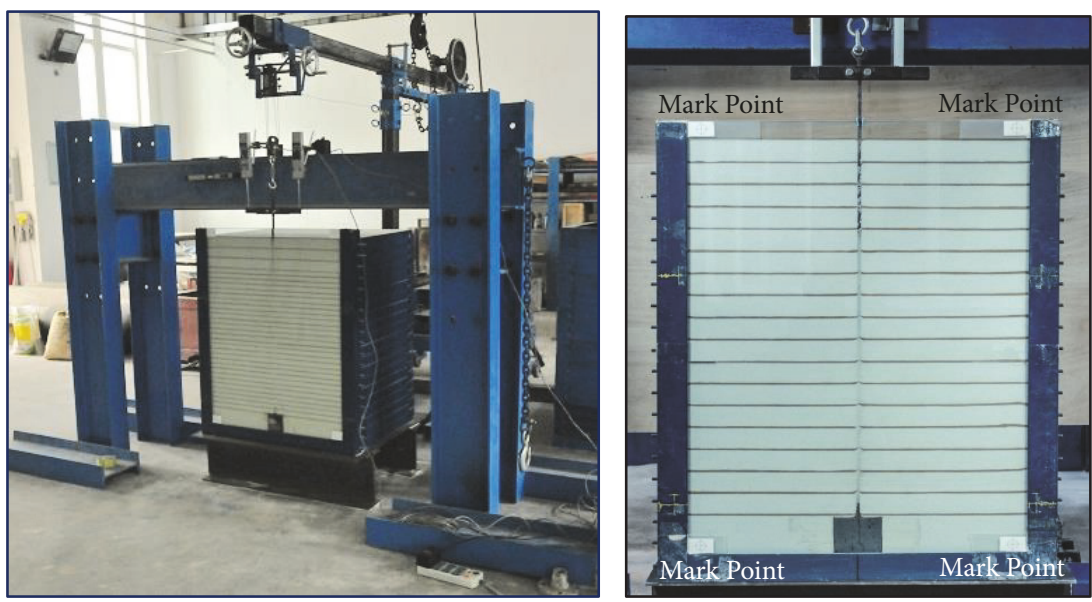

FIGURE 13: Test device of soil deformation state around an anchor.

scope containing four mark points and then applied loading on the model. Each load step was approximately $1 \mathrm{~mm}$, and there was a gap of 3 min between every consecutive load step to stabilize the load and capture a photo.

After a displacement of $60 \mathrm{~mm}$ was reached, one test was completed. During data processing, the target scope in a sequence of images was meshed uniformly. Based on the mesh of the first image, the displacements of the grids and strain of the mesh in the image of every load step were calculated. Finally, researcher analyzed the soil deformation state according to the deformation mesh in the photos, as depicted in Figure 14.

3.3. Test Result and Analysis. Based on the shallow and deep behaviors of the underreamed anchors, the tests of underreamed anchor models buried at depths of $850 \mathrm{~mm}$ and 350 $\mathrm{mm}$ were performed separately.

Figure 15 exhibits the displacement vector state of the soil around the underreamed anchor at a depth of $850 \mathrm{~mm}$ when the anchor displacement is $5 \mathrm{~mm}, 10 \mathrm{~mm}$, and $40 \mathrm{~mm}$. For 


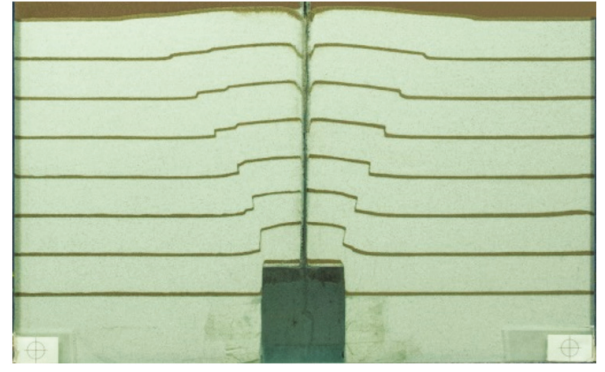

(a)

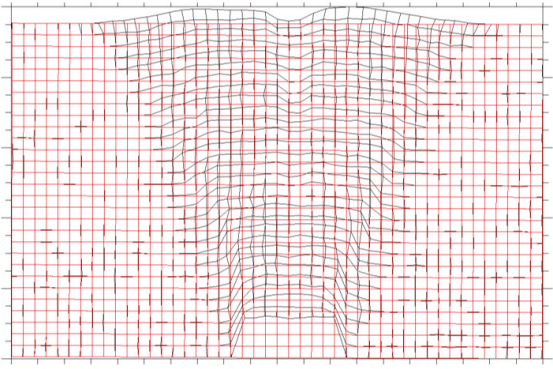

(b)

Figure 14: Sand deformation and deformation mesh of the soil around an underreamed anchor. (a) Sand deformation. (b) Deformation mesh.

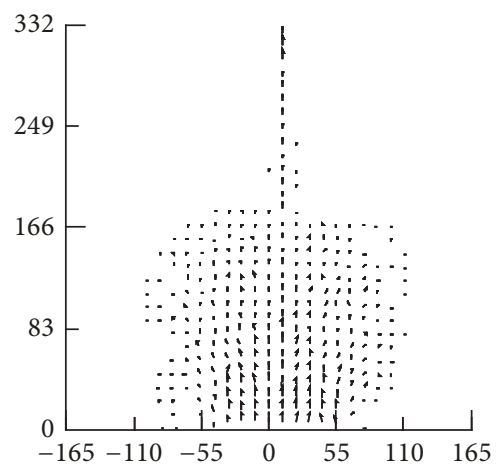

(a)

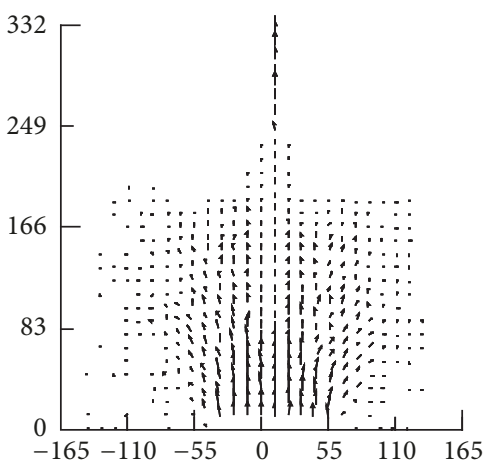

(b)

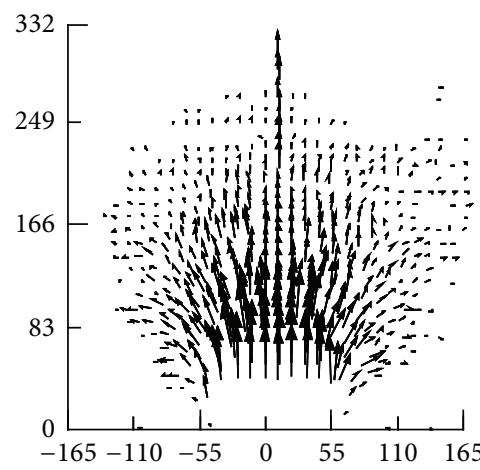

(c)

FIGURE 15: Diagrams of the displacement vector of the deep anchor (unit: mm). (a) Displacement of $5 \mathrm{~mm}$. (b) Displacement of $10 \mathrm{~mm}$. (c) Displacement of $40 \mathrm{~mm}$.

clarity, the plots omit the areas where the particles are not moving. According to the vector distribution in the three plots, the moving particles are typically in a close range near the expanded section. When the anchor moves $5 \mathrm{~mm}$ upward, the particles move against the expanded section, displacement vector state is radial, and deformation form completely resembles a ball, whose dimensions are $165 \mathrm{~mm}$ in height and $220 \mathrm{~mm}$ in width. As the anchor continues to move, the displacement reaches $10 \mathrm{~mm}$ and deformation form becomes larger, with a height of $180 \mathrm{~mm}$ and width of 275 $\mathrm{mm}$. When the displacement of the anchor reaches $40 \mathrm{~mm}$, the displacement of the soil in the deformation area becomes significantly large, and the height and width are $250 \mathrm{~mm}$ and $300 \mathrm{~mm}$, respectively. It can be observed that even if the deep anchor undergoes a large displacement, the soil area affected by the anchor is typically under the foundation surface.

Figure 16 shows the shear strain cloud photos of the soil when the displacement of the deep anchor reaches $5 \mathrm{~mm}, 10$ $\mathrm{mm}$, and $40 \mathrm{~mm}$.

Figure 16(a) shows that shear regions appear near the outer part of the top surface of the expanded section when the load displacement is $5 \mathrm{~mm}$. This illustrates that stress concentration occurs near the outer part of the top surface of the expanded section, and the high stress level leads to shear failure near these parts. As the load displacement increases, the small shear regions become shear bands toward upward and outward, as exhibited in Figure 16(b). In Figure 16(c), when the deep anchor undergoes a large displacement, the shear bands originate near the expanded sections and converge immediately above the expanded section. The above test phenomenon and analysis can explain the intrinsic mechanism of the stress distribution and development laws of the end bearing force depicted in Figure 8(c). At the start of the loading, a high stress level appears on the outer part of the surface of the expanded section, as shown in Figure 9(a). Moreover, small shear zones appear in the soil near the outer part, as illustrated in Figure 16(a). As the load increases, shear failure occurs in more areas in the soil near the outer part, and the soil cannot endure more load. As the load increases, the soil near the medium part begins bearing more resistance, and the stress on the medium part of the upper surface of the expanded section becomes higher, as shown in Figure 9(b).

For comparison, Figure 17 displays the displacement vector states in the soil when the load displacements of the shallow anchor are $2.5 \mathrm{~mm}, 5 \mathrm{~mm}$, and $40 \mathrm{~mm}$.

It is shown in Figure 17(a) that the soil particles move away from the expanded section before the failure of the shallow anchor. Moreover, the moved area of the soil does not reach the top of the foundation. With the load becoming larger, the displacement reaches $5 \mathrm{~mm}$ and the total resistance attains nearly a peak value in Figure 11(a); the moved soil area reaches the surface of the foundation, as displayed in Figure 17(b). Figure 17(c) exhibits that the anchor displacement reaches $40 \mathrm{~mm}$. At this load level, a large triangular deformation area appears above the expanded section, and, in the foundation, there occurs an inverted truncated cone 

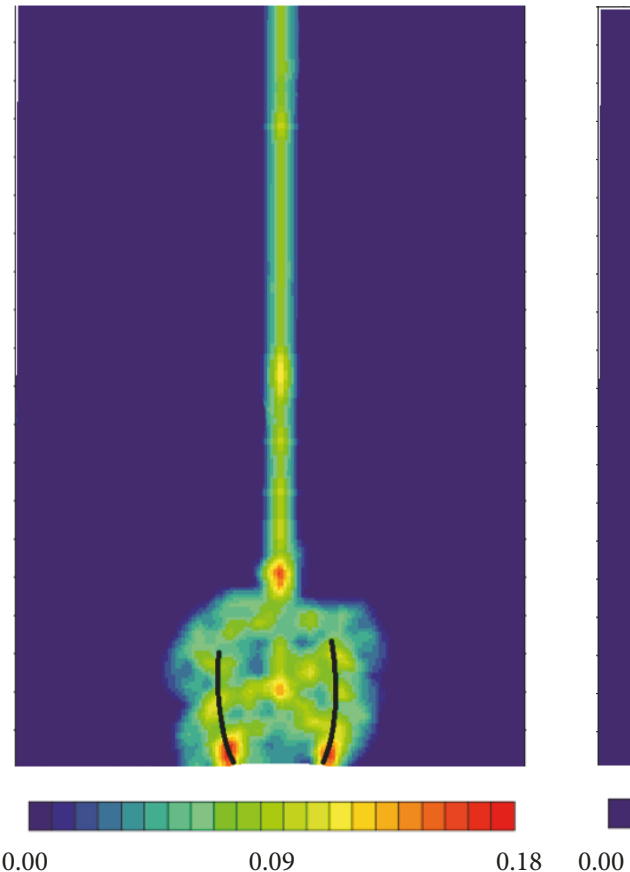

(a)

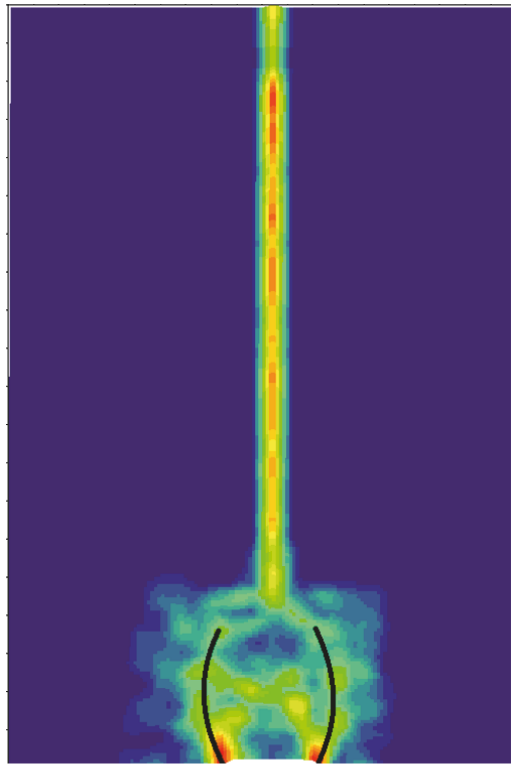

0.18

(b)

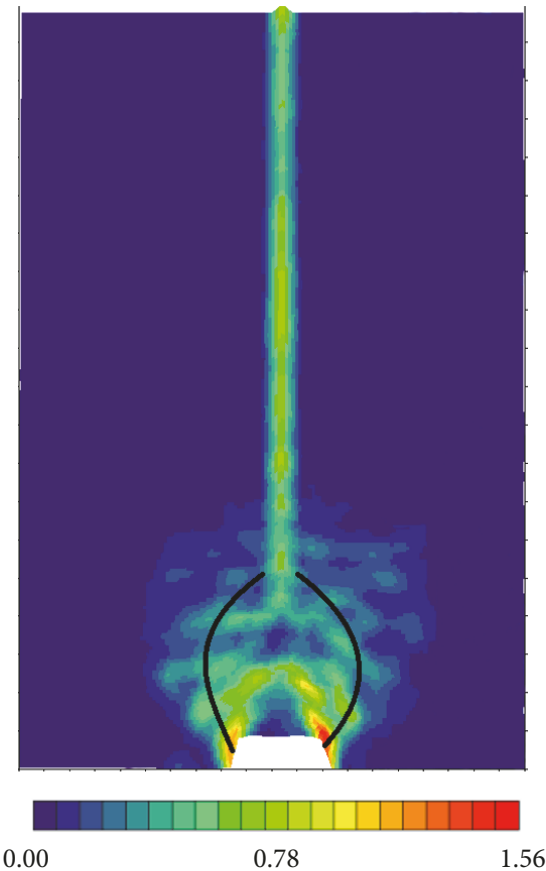

(c)

Figure 16: Cloud pictures of the shear strain of the deep anchor. (a) Displacement of $5 \mathrm{~mm}$. (b) Displacement of $10 \mathrm{~mm}$. (c) Displacement of $40 \mathrm{~mm}$.

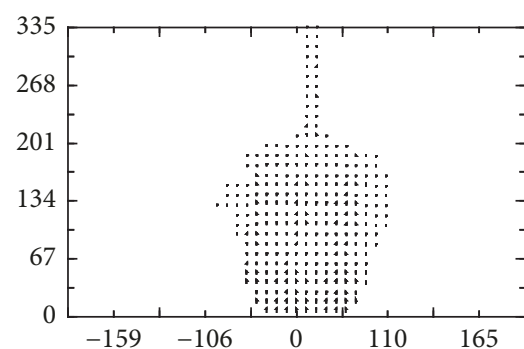

(a)

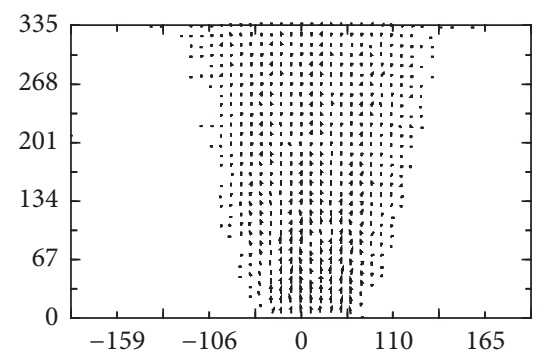

(b)

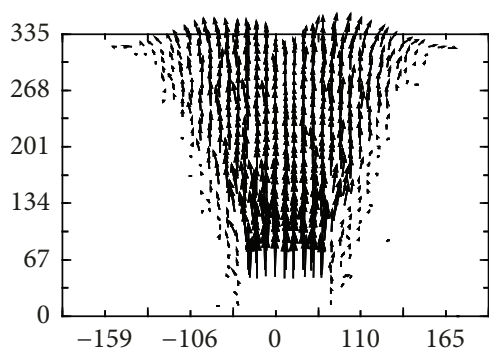

(c)

FIGURE 17: Diagrams of the displacement vector of the shallow anchor (unit: $\mathrm{mm}$ ). (a) Displacement of $2.5 \mathrm{~mm}$. (b) Displacement of $5 \mathrm{~mm}$. (c) Displacement of $40 \mathrm{~mm}$.

slip body. Moreover, on the foundation surface, there appears a high rising region; the soil particles near the outside of the rising region flow horizontally.

To discuss the mechanism of the shallow anchor in detail, Figure 18 presents the shear strain cloud pictures of the soil when the displacement of the anchor is $2.5 \mathrm{~mm}, 5 \mathrm{~mm}$, and $40 \mathrm{~mm}$.

Figure 18(a) illustrates that when the displacement of the anchor is $2.5 \mathrm{~mm}$, shear bands appear near the upper surface of the expanded section but do not reach the surface of the foundation. The shear bands grow and reach the surface of the foundation when the displacement reaches $5 \mathrm{~mm}$, as shown in Figure 18(b). A general shear failure occurs along with the shear bands. Because there is no more soil participating to provide shearing capacity, the anchor has maximum anchor resistance, as exhibited in Figure 11(a). Moreover, the shear bands cause the soil in the shear area to separate from the surrounding soil, and the stress on the upper surface of the expanded section decreases, as shown in Figure 11(c). As the loading progresses, the shear failure zone becomes $\mathrm{v}$ in Figure 18(c), and the shear strain of the soil also becomes higher.

Furthermore, the analysis of the capacity of the anchors is as follows.

For a deep anchor, in the entire loading process, even when the displacement is large, the shear failure area is typically near the expanded section and does not reach the surface of the foundation; a local shear failure occurs in the soil. Thus, during the loading process of a deep anchor, typically there is more soil providing shear capacity. Therefore, the Q-s curve of a deep anchor monotonically increases, as shown in Figure 8(a). For a shallow anchor, even when the load level is low, a shear failure area develops on the surface of the foundation, and a general shear failure occurs. After the 


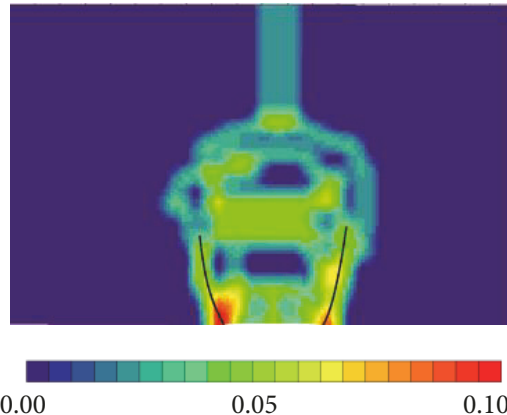

(a)

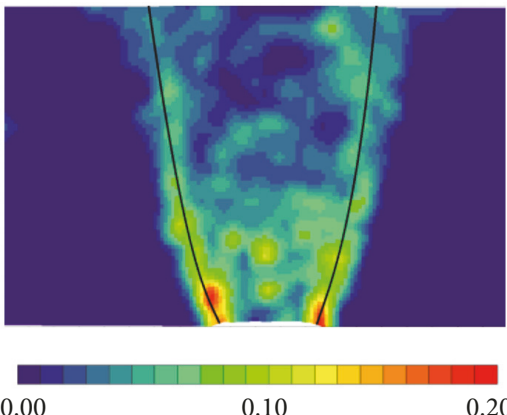

(b)

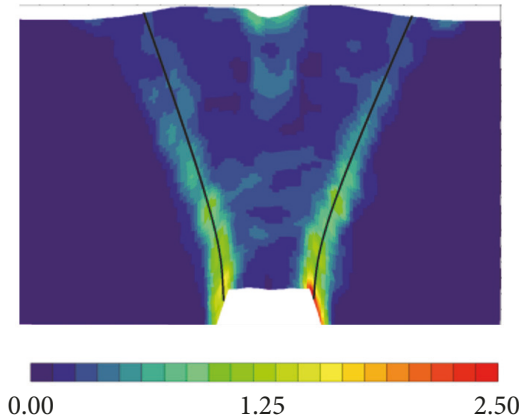

(c)

Figure 18: Cloud pictures of the shear strain of the shallow anchor. (a) Displacement of $2.5 \mathrm{~mm}$. (b) Displacement of $5 \mathrm{~mm}$. (c) Displacement of $40 \mathrm{~mm}$.

failure, the foundation cannot provide shear capacity, and the entire anchor only has a residual bearing capacity including the gravity of the failure area and remaining friction between the expanded section and corresponding soil. Therefore, the Q-s curve of a shallow anchor behaves as depicted in Figure 11(a).

\section{Conclusions}

Considering a regular underreamed anchor as a prototype, model tests in sand were performed in this study. Accordingly, first, the force distribution principle of the underreamed ground anchor in sand was acquired by the FBG sensing method. Then the soil reaction around the underreamed anchor was analyzed by digital photogrammetry and symmetrical model test methods. Based on the model test results, the bearing mechanism and interaction relationships between the underreamed anchor and soil around were discussed.

(1) The bearing capacity of an underreamed ground anchor includes the end bearing force and friction. Moreover, the friction takes effect at the starts of loading. However, after a certain displacement, the end bearing force plays a more important role.

(2) The bearing capacity of an underreamed anchor mainly originates from the end bearing force of the expanded section. The end bearing force accounts for $68 \%$ of the total bearing capacity of a deep anchor and 60\% for a shallow anchor in the test environment. Because of the end bearing force of the expanded section, an underreamed anchor offers advantages over normal shaft anchors.

(3) The relationship between the end bearing force of an underreamed anchor and the embedment depth is a positive correlation. Moreover, the relationship between the end bearing force of a deep anchor and the embedment depth is a significant linear correlation.

(4) The stress state on the upper surface of the expanded section of an underreamed anchor changes during loading, and it performs as an inverted rigid foundation.

(5) Under the same geological condition, the underreamed ground anchor can be a deep embedded type and shallow embedded type. During the loading process of a deep underreamed anchor, the anchor capacity continually increases, and a local shear failure occurs in the soil around the expanded section. For a shallow underreamed anchor, initially, the anchor capacity increases, and, after reaching a peak value, it decreases. The anchor capacity of a shallow anchor mainly originates from the shear friction before failure, and a general shear failure occurs easily in the soil around the expanded section.

(6) According to the two mechanism types of an underreamed anchor, there is a certain critical embedment depth that distinguishes between a shallow and deep anchor under a certain geological condition. In engineering practice, the designer should ensure that the underreamed anchor is embedded deeper than the critical embedment depth to achieve safety and stability.

\section{Data Availability}

The data from studies used for the analysis are provided in Google Drive: https://drive.google.com/open?id=1yu7tb1_ iF2dOVLIzZQc1DW9RZCfezxE_ or they are available from the corresponding author upon request.

\section{Conflicts of Interest}

The authors declare that they have no conflicts of interest.

\section{Authors' Contributions}

For the research work, Gang Guo and Zhong Liu conceived and designed the experiments; Gang Guo, Yibing Deng, and Jiqiang Zhang performed the experiments and analyzed the data; Zhong Liu and Aiping Tang contributed the test materials and analysis tools; Gang Guo wrote the paper.

\section{Acknowledgments}

This work was supported by Beijing Natural Science Foundation (8184098).

\section{References}

[1] A. D. Barley, "Theory and practice of the single bore multiple anchor system," in Proceedings of the Anchors in Theory and 
Practice, International Symposium on Anchors in Theory and Practice, Saltzburg, Austria, 1995.

[2] I. W. Farmer, "Stress distribution along a resin grouted rock anchor," Int. J. Rock Mech. Min. Sci. Geomech. Abstr, vol. 12, pp. 347-351, 1975.

[3] J. Chalmovský and L. Miča, "Influence of pressure grouting on the anchors carrying capacity in fine grained soil," in Proceedings of the 11th International Scientific Conference on Modern Building Materials, Structures and Techniques, MBMST 2013, pp. 222-231, Lithuania, May 2013.

[4] F. Ren, S. Wu, Y. Liu, and J. Liu, "Study on effective anchorage length of anchor cable based on Gauss's function," IOP Conference Series: Earth and Environmental Science, vol. 94, p. 012203, 2017.

[5] H. J. Liao, K. W. Wu, and S. C. Shu, "Uplift behaviour of a coneshape anchor in sand. Ground Anchors and Anchored Structures," in Proceedings of the International Conference Organized by the Institution of Civil Engineers and held in, pp. 401-410, London, UK, 1997.

[6] H. J. Liao and S. T. Hsu, "Uplift behavior of blade-underreamed anchors in silty sand," Journal of Geotechnical and Geoenvironmental Engineering, vol. 129, no. 6, pp. 560-568, 2003.

[7] K. R. Massarsch, K. Oikawa, Y. Ichihashi et al., "Design and practical application of soilex anchors. ground anchors and anchored structures," in Proceedings of the International Conference Organized by the Institution of Civil Engineers and held in, pp. 20-21, London, UK, 1997.

[8] L. Hobst and J. Zajic, Anchoring in Rock and Soil, S. J. Beijing, Ed., Central Research Institute of Building and Construction, Ministry of Metallurgical Industry, 1986.

[9] L. K. Cheng, J. L. Fan, J. Han et al., Ground Anchor, Architecture and Building Press, Beijing, China, 2000.

[10] H. Park, S. R. Lee, N. K. Kim, and T. H. Kim, "A numerical study of the pullout behavior of grout anchors underreamed by pulse discharge technology," Computers \& Geosciences, vol. 47, no. 1 , pp. 78-90, 2013.

[11] H. H. Zhu, G. X. Mei, and M. Xu, "Experimental and numerical investigation of uplift behavior of umbrella-shaped ground anchor," Geomechanics amp; Engineering, vol. 7, no. 2, pp. 165181, 2014.

[12] Z. Liu, G. Guo, Y. Zhang et al., "Construction technology and application of under-reamed anchor with capsule," Chinese Journal of Geotechnical Engineering, vol. 36, no. 2, pp. 205-211, 2014.

[13] The British Standards Institution, Code of Practice for Grouted Anchors, BSI Standards Limited, 2015.

[14] Chinese Code, "Technical specification for under-reamed anchor by jet grouting (JGJ/T282-2012),” Tech. Rep., Chinese Building and Construction Press., Beijing, China, 2012.

[15] G. S. Littlejohn, "Soil anchors," in Proceedings of the Conference on Ground Engineering, ICE London, 1970.

[16] R. H. Bassett, "Underreamed ground anchors," Revue Française de Géotechnique, no. 3, pp. 11-17, 1978.

[17] Q.-Y. Zeng, X.-Y. Yang, and C.-Y. Yang, "Mechanical mechanism and calculation method of bit expanded anchor rods," Yantu Lixue/Rock and Soil Mechanics, vol. 31, no. 5, pp. 13591367, 2010.

[18] R.-J. Zhang, J.-J. Zheng, P.-Y. Li, J. Zhang, and S. Yu, "A method for predicting mechanical behaviour of HPJG-Anchors - Part II: Prediction procedure, verifications and parametric studies," Computers \& Geosciences, vol. 45, pp. 44-52, 2012.
[19] S. T. Hsu, "A numerical study on the uplift behavior of underreamed anchors in silty sand," Advanced Materials Research, vol. 189-193, pp. 2013-2018, 2011.

[20] S. T. Hsu, C. C. Wang, S. Wu, and H. C. Tung, "Computer simulation on the uplift behavior of an arrayed under-reamed anchor group in dense sand," International Conference on Systems and Informatics. IEEE, pp. 546-551, 2017.

[21] B. Walz, Bodenmechanische Modelltechnik Als Mittel Zur Bemessung Von Grundbauwerken, Universitaet-GH Wuppertal Fachbereich Bautechnik, 1982.

[22] S. C. Chian, M. E. Stringer, and S. P. G. Madabhushi, "Use of automatic sand pourers for loose sand models," in Proceedings of the 7th International Conference on Physical Modelling in Geotechnics 2010, ICPMG 2010, pp. 117-121, Switzerland, July 2010.

[23] Y. Li, H. Zhu, and H. Jing, "Experimental Observation of Shear Deformation Patterns in Sands using Digital Photogrammetry," in Proceedings of the GeoShanghai International Conference 2006, pp. 120-127, Shanghai, China. 


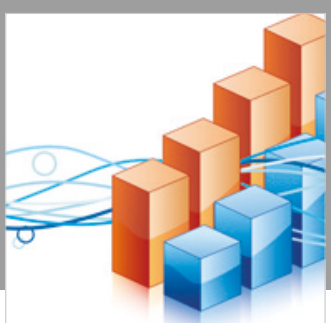

Advances in

Operations Research

\section{-n-m}
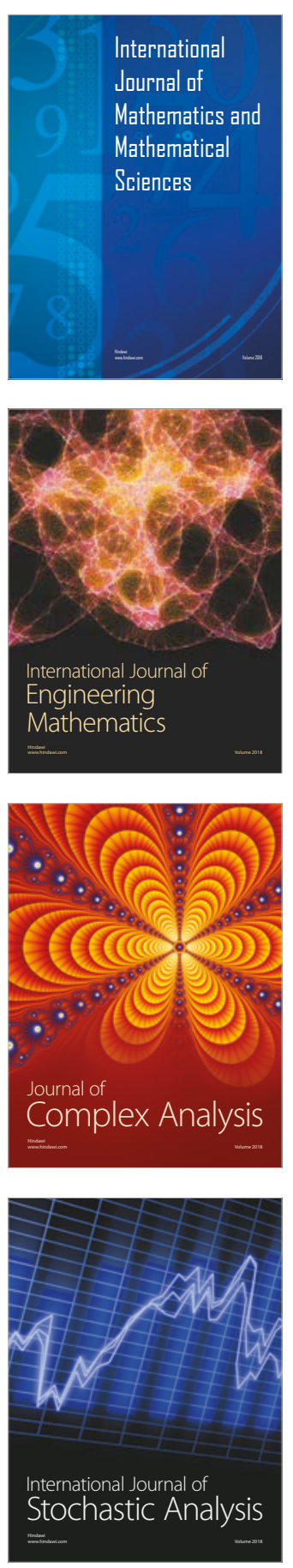
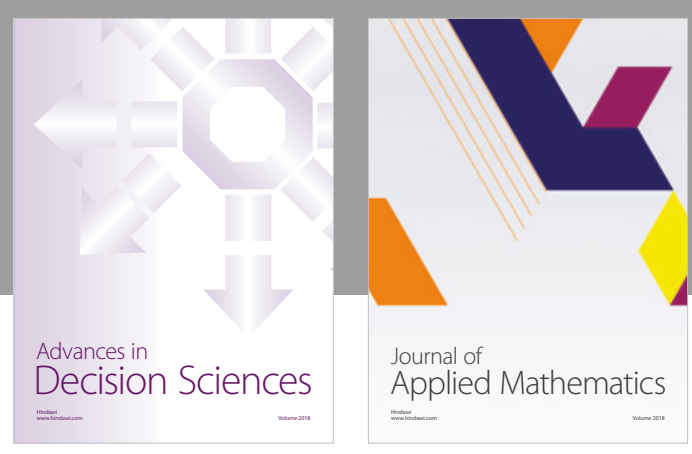

Journal of

Applied Mathematics
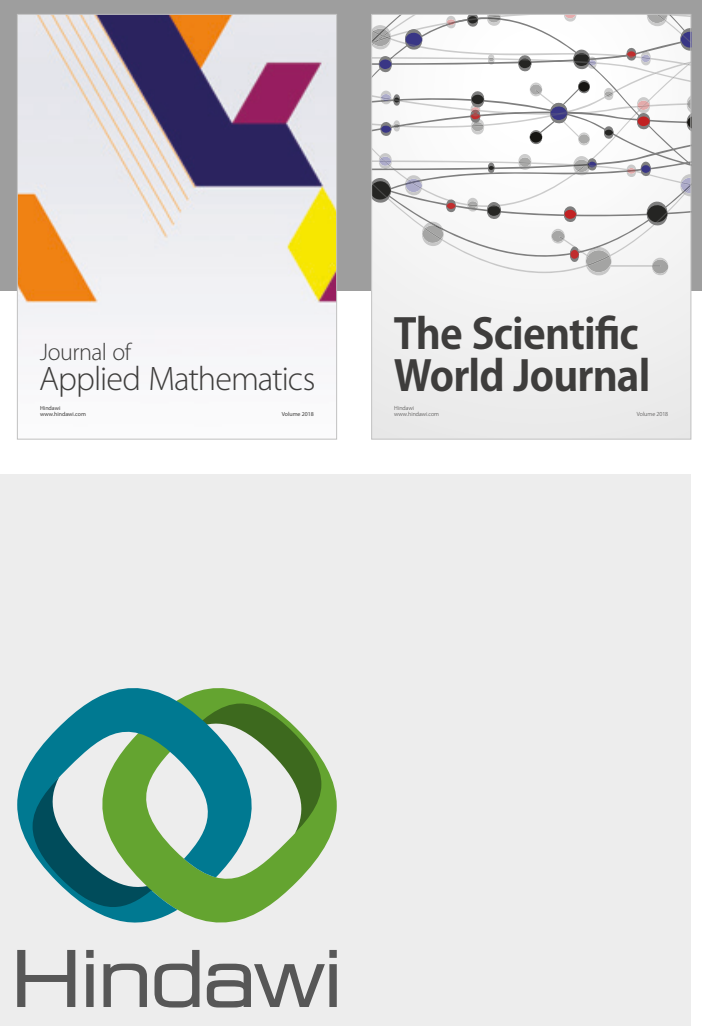

Submit your manuscripts at

www.hindawi.com

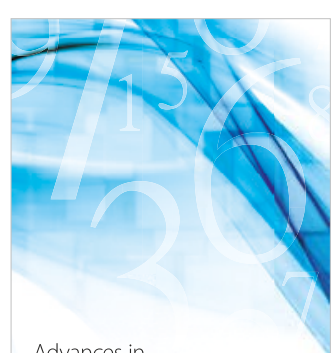

Advances in
Numerical Analysis
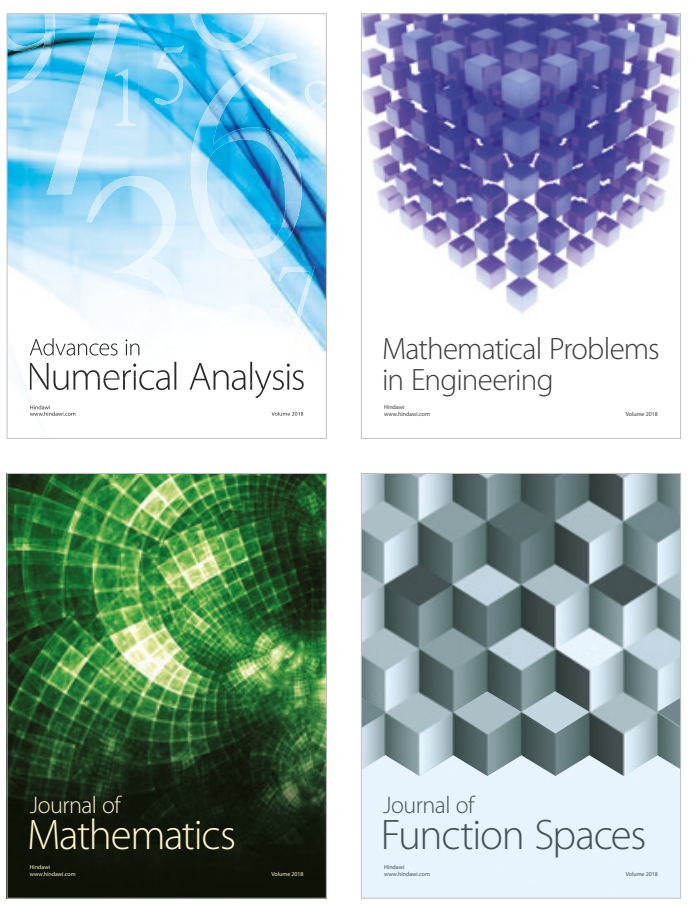

Mathematical Problems in Engineering

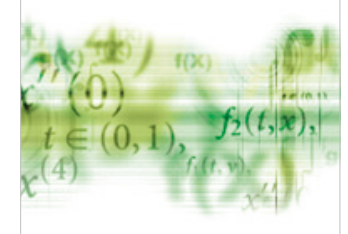

International Journal of

Differential Equations

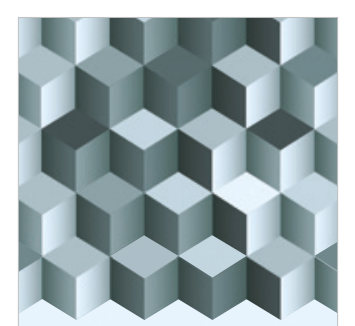

Journal of

Function Spaces

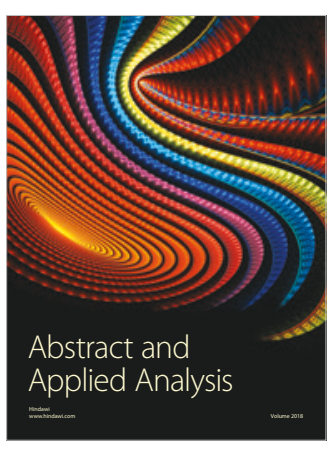

The Scientific

World Journal

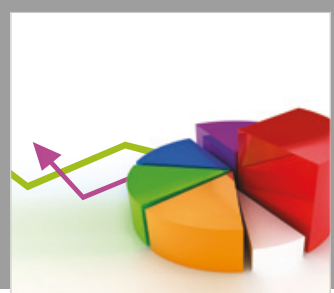

Journal of

Probability and Statistics
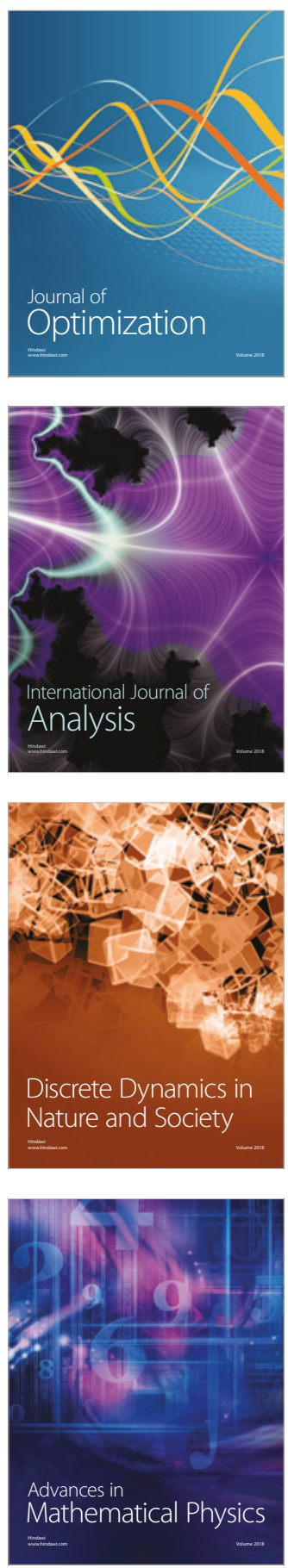